\title{
Publication Misdemeanour
}

\section{Two Articles for Comparison}

\section{Article A}

\section{APACHE II score in massive upper gastrointestinal haemorrhage from peptic ulcer: prognostic value and potential clinical applications}

This study examined the prognostic value of the APACHE II scoring system in patients undergoing emergency operations for bleeding peptic ulcer. There were 96 operations for gastric ulcers and 58 for duodenal ulcers. The mean scores in survivors and in patients who died were 10.8 and 17.5 respectively. None of the 66 patients with an APACHE II score $<11$ died, while the mortality rate in those scored $>10$ was $22 \%$. In patients scored $>10$ non-resective procedures carried less risk of mortality than gastrectomy. The APACHE II score is useful when measuring the severity of the acute disease and predicting the outcome in these patients. If used in daily practice it may assist the surgeon in stratifying patients into a low-risk group (score $<11$ ) in which major operations are well tolerated and outcome is favourable and a high-risk group (score $>10$ ) in which the risk of mortality is high and the performance of procedures of lesser magnitude is probably more likely to improve survival.

Key Words: APACHE II, outcome prediction, upper gastrointestinal haemorrhage, emergency gastroduodenal operations

The procedure of choice for the surgical control of a bleeding peptic ulcer is controversial. While some authors advocate the use of truncal vagotomy and antrectomy ( $\mathrm{TV}+\mathrm{A})$ for a bleeding duodenal ulcer, others claim that truncal vagotomy and a drainage procedure $(\mathrm{TV}+\mathrm{D})$ is safer. The same argument involves the management of bleeding gastric ulcers. Whilst partial gastrectomy continues to be the procedure of choice in many major centres, others attribute lower mortality rates to more conservative operations such as $\mathrm{TV}+\mathrm{D}$ or simple undersewing of the ulcer alone.

The comparison of results is distorted by the fact that sicker patients are usually selected for the more conservative operations. Thus, for example, McGuire and Horsley, operating on bleeding duodenal ulcers, cited a mortality rate of $21 \%$ for $\mathrm{TV}+\mathrm{A}$ and $45 \%$ for $\mathrm{TV}+\mathrm{D}$. It is widely ...

Written by: M. Schein and G. Gecelter Published: Br J Surg 1989;76:733-736.

This editor's note has already been published in the British Journal of Surgery 1999;86:598-599.

\section{Article B \\ APACHE II score in massive upper gastrointestinal haemorrhage from peptic ulcer}

\section{Abstract}

This retrospective study examined the prognostic value of the APACHE II scoring system in patients undergoing emergency operations for bleeding peptic ulcer. Between 1980-1997 there were 228 patients who had operated emergency for bleeding peptic ulcer. There were 57 operations (25\%) for gastric ulcers and $171(75 \%)$ for duodenal ulcers. There were $48(21.2 \%)$ female, 180 (78.9\%) male and the median age was $46.0 \pm 16.4$ (range 15-81). In the group who had operated for gastric ulcer male/female ratio was $47 / 10$ and the median age was $49.4 \pm 16.4$. In the group who had operated for duodenal ulcer male/female ratio was $133 / 38$ and the median age was $44.8 \pm 16.3$. The mean APACHE II scores in survivors and in patients who died were 5.29 and 9.27 respectively. In patients who had high APACHE II scores, vagotomy + drainage procedures carried less risk of mortality than vagotomy + resection.

If used in daily practice it may assist the surgeon in stratifying patients into a low-risk group in which major operations are well tolerated and outcome is favourable and high-risk group in which the risk of mortality is high and the performance of procedures of lesser magnitude is probably more likely to improve survival.

Key Words: APACHE II, upper gastrointestinal haemorrhage, emergency gastroduodenal operations

\section{Introduction}

The procedure of choice for the surgical control of a bleeding peptic ulcer is controversial. While some authors advocate the use of truncal vagotomy and antrectomy $(\mathrm{TV}+\mathrm{A})$ for a bleeding duodenal ulcer, others claim that truncal vagotomy and a drainage procedure $(\mathrm{TV}+\mathrm{D})$ is safer. The same argument involves the management of bleeding gastric ulcers. Whilst partial gastrectomy continues to be the procedure of choice in many major centres, others attribute lower mortality rates to more conservative operations such as $\mathrm{TV}+\mathrm{D}$ or simple undersewing of the ulcer alone.

The comparison of results is distorted by the fact that sicker patients are usually selected for the more conservative operations. Thus, for example, McGuire and Horsley, operating on bleeding duodenal ulcers, cited a mortality rate of $21 \%$ for TV+A and $45 \%$ for TV+D. It is widely ...

Submitted by: Okan Dalyan, Haluk Demiryurek, Fatih Kaya, Bulent Belevi of the University of Cukurova, Dept of Gen Surgery, Adana, Turkey

To: Digestive Surgery, December 1998

\section{KARGER \\ Fax + 41613061234 \\ E-Mail karger@karger.ch}

๑ 1999 S. Karger AG, Basel www. karger.com
Accessible online at: http://BioMedNet.com/karger 
It was by chance that Dr. Markus Büchler, Editor of Digestive Surgery, sent Article B to be refereed by one of the authors of Article A, who recognized the text. If not spotted by this referee, the article may well have been published in Digestive Surgery and would have represented a form of plagiarism. The paper from Turkey presumably used local data within the total text and results framework of Article A.

The first author of Article B has expressed sincere regrets at this incident and offers 'insufficiency of English' and 'definitely my aim was not plagiarism' as explanations. The situation was compounded by the fact that Doctors Demiryurek, Kaya and Belevi did not see and agree the article before submission. This is confirmed by correspondence from all alleged authors of Article B. The editors of the BJS and Digestive Surgery believe that Drs Demiryurek, Kaya and Belevi were unaware of these matters until alerted to the situation and are, therefore, innocent of any publishing misdemeanour.

$B J S$ and Digestive Surgery are dismayed to be involved in such a situation. This article appears in both Journals as an agreed statement between the editors, higher officers and publishers, to be read by the surgical scientific community. The recommendations following this incident are:

(i) If your first language is not English, do seek help in the writing of your paper. Do not 'lift' text from existing papers into your own manuscript without appropriate acknowledgement;

(ii) As a supervisor of trainees, be responsible for advising and guiding first attempts at surgical writing;

(iii) It is best practise to submit signed declarations of authorship from all named authors at the time of submission.

The BJS and Digestive Surgery will not condone any examples of this type of behaviour and will declare such events in their pages and send copies of these notices to host universities, hospitals and institutions. These Journals support the stance of other editors and journals in attempts to reduce these instances to a minimum through groupings such as The Committee on Publication Ethics [1,2].
J.R. Farndon
M.W. Büchler
Editor - for BJS
Editor - for Digestive Surgery

\section{References}

Farthing MJG: Coping with fraud. Lancet 1998;352(suppl IV):11.

2 Farthing M: Gut in 1999 (editorial). Gut 1999;44:1. 